\title{
Eşitlik, Erişilebilirlik ve Toplu Taşıma
}

\author{
Richard Szeri ${ }^{1}$ \\ ORCID: 0000-0002-0158-1981
}

\author{
İrem Ayhan Selçuk ${ }^{2}$ \\ ORCID: 0000-0002-9797-800X
}

\section{Öz}

Toplumsal eşitlik ve sürdürülebilir gelişme açısından toplu taşıma sistemlerinin geliştirilmesi ve yönetilmesi kritik öneme sahiptir. Bu çalışma; bir yerleşmede bulunan konut alanları, çalışma alanları ve diğer kentsel hizmet alanlarına erişim imkanları açısından; kentte yaşayan tüm gruplara eşit ulaşım hizmeti sağlama konusunda; ulusal ve uluslararası alandaki konuya bakış açılarım, izlenen politikaları, kullanılan yöntemleri ve alınan sonuçları incelemektedir. Bu makalenin yazımındaki amaç toplu taşıma sistemlerinin yönetimindeki başarı ile sosyal adaletin oluşturulması ve firsat eşitliğinin să̆lanması arasındaki güçlü ilişkiye dikkat çekmektir. Bununla birlikte; toplumu oluşturan bireylerin ulaşımdan adil yararlanmasını gözeten bir ulaşım sistemi oluşturulmasında şehir plancılara, ulaşım plancılara ve yerel/merkezi yönetimlere düşen sorumluluklara dikkat çekmektir. Bu kapsamda ulaşım hakkı ve ulaşım hizmetlerinin adil dağılımı konusundaki mevcut literatür incelenerek; çalışma kapsamında tartışmaya açılmıştır. Mekansal planlama çalışmalarının sürdürülmesinde; plan hiyerarşisi, ölçekler arası ilişki ve mekansal plan türüne bă̆lı kararlar açısından; planlamanın kamu yararı ve eşitlik ilkesinin sağlanmasında; ulaşım sistemi, çalışma alanları ve kentsel hizmet alanlarının kurgulanması konusunu tartışmaya açıyor olması; bu çalışmanın bilime katkısını oluşturmaktadır. Çalışma 2017.KB.FEN.2016 nolu Dokuz Eylül Üniversitesi Rektörlüğ̈̈ Bilimsel Araştırma Projeler Birimi (BAP) tarafindan desteklenmekte olup; Dokuz Eylül Üniversitesi Fen Bilimleri Enstitüsü tamamlanmamış yüksek lisans tezinin bir ürünüdür

Anahtar Kelimeler: Erişilebilirlik, Eşitlik, Planlama, Toplumsal Eşitlik, Toplu Taşıma Sistemleri, Ulaşım Hakkı

\footnotetext{
${ }^{1}$ Berlin (Almanya)de FlixMobility Şirketinde ulaşım plancısı, E-mail: szeri.richard@gmail.com

${ }^{2}$ Dr. Öğr. Üyesi, Dokuz Eylül Üniversitesi, E-mail: irem.ayhan@deu.edu.tr

idealkent @ C Kent Araştırmaları Dergisi (Journal of Urban Studies)

http://idealkentdergisi.com

Geliş Tarihi Received Date: 29.01.2019 Kabul Tarihi Accepted Date: 31.12.2019
} 


\title{
Equity, Accessibility and Public Transportation
}

\author{
Richard Szeri ${ }^{3}$ \\ ORCID: 0000-0002-0158-1981
}

\author{
İrem Ayhan Selçuk 4 \\ ORCID: 0000-0002-9797-800X
}

\begin{abstract}
Developing and managing the public transportation systems have a critical importance on the aspect of social equity and sustainability. This work is examining national and international perspectives, policies followed, methods used and results achieved in providing equal transportation service to all groups living in the city; in terms of housing areas, working areas and access to the other urban service areas in a settlement. The aim of the study is to emphasize the strong relation between management of public transportation systems, settlement of social justice and ensuring equality of opportunity. Also; to draw attention to the responsibilities of urban planners, transportation planners and local / central governments; to establish a transport system that takes into consideration the fair utilization of the public. Literature about the determinants of fair distribution of access and right of transportation is examined and discussed in the context of the study. This study contributes to the science with discussion of the relation between transportation, working areas and urban services in providing public benefit and equality principle of planning; in terms of planning hierarchy, relationship between scales and decisions based on spatial plan type. This study is supporting by 2017.KB.FEN.2016 Dokuz Eylül University Rektorship, Department of Scientific Research Project (BAP) and same time; is the product of an incomplete master's thesis of The Graduate School of Natural and Applied Sciences.
\end{abstract}

Keywords: Accessibility, Planning, Public Transportation System, Transportation Right, Social Equality.

\footnotetext{
${ }^{3}$ Transportation planner at FlixMobility (Flixbus) in Germany, E-mail: szeri.richard@gmail.com

${ }^{4}$ Asst. Prof. Dr., Dokuz Eylül University, E-mail: irem.ayhan@deu.edu.tr

idealkent (c) Kent Araştırmaları Dergisi (Journal of Urban Studies) 


\section{Giriş}

Dönemsel olarak nitelik ve niceliği değişse de; insanın varlığı ve yaşam alışkanlıklarına bağlı olarak mekan üzerinde planlı olarak önerilen ya da plansız olarak gelişen çalışma alanı, konut alanı, sosyo-kültürel alanlar, eğitim ve sağlık alanları gibi pek çok fonksiyon; eğer sözkonusu olan bilgi transferi değilse; kendi aralarındaki ilişkiyi sürdürebilmek için mekansal anlamda işleyişi aksatmayacak nitelikte ve amacına uygun ulaşım türlerini de destekleyen iyi bir ulaşım altyapısına ihtiyaç duyar.

Fonksiyonlar arasında kurgulanan ulaşım altyapısı genellikle iki amaca hizmet eder: bireylerin taşınması, ya da eşyanın taşınması. Sözkonusu taşıma hizmeti; bireylerin ulaşım türü tercihlerine bağlı olarak; taşınma talebine hangi düzeyde hizmet edebiliyorsa; o derece başarılıdır. Eğer internet yard1mıyla minimize edilemiyorsa; taşınma talebinin maksimizasyonu esastır.

Taşınma talebinin karşılanma düzeyi ise daha alt başlıklarda değerlendirilmesi gereken konfor, güvenlik, hız, ücret vb. pek çok değişkenin bileşiminden oluşmaktadır. Önemli olan bireyin sadece A noktasından B noktasına taşınma işinin gerçekleştirilmesi değil; taşıma işleminin hangi koşullarda, hangi ulaşım seçenekleriyle/alternatiflerle, hangi ücretlerle ve nasıl gerçekleştirildiğidir.

Bunun nedeni kentsel ya da kırsal sistemler/yönetimler tarafından mevcutta arz olunan ulaşım türü tercihlerinin ve bu tercihlere ait özelliklerin; bireylerin yolculuğa başlamak/başlayabilmek ya da başlamamak/başlayamamak konusundaki kararlarında zaruri ya da keyfi olarak etkili olması nedeniyle ortaya çıkan ve toplumun bazı kesimleri için kentsel/kırsal hizmetlerden eşit oranda yararlanma hakkı konusunda engel oluşturan faktörleri minimize etmekteki gerekliliktir.

Dolayısıyla kentin ya da kırın; kullanıcılarına arz etmiş olduğu çalışma, konut ya da sosyal hizmet alanları; ulaşım altyapısıyla tercihli olarak desteklendiği ve ilişkilendirildiği ölçüde gerçek amacına ulaşacak, varlık nedeninin gereklerini yerine getirerek yalnılaşmaktan ya da atıl kalmaktan kurtulacak, ekonomik işlerliğini sürdürecek ve hizmet verdiği bireylerin kent/kır ya da ülke ekonomisine artı değer sağlamasında rol sahibi olacaktır.

Bu çalışmanın amacl; toplum içerisinde dezavantajlı olarak tanımlanan bireylerle dezavantajlı olarak tanımlanmayan bireylerin; yani "herkesin" kentsel hizmetlerden eşit oranda pay almasında önemli bir araç olan toplu taşıma sistemlerinin; toplumun tüm bireylerinin firsat eşitliğine sahip olmasındaki önemine dikkat çekmektir. Çalışma 2017.KB.FEN.2016 nolu Dokuz Eylül 
Üniversitesi Rektörlüğü Bilimsel Araştırma Projeler Birimi (BAP) tarafından da desteklenmektedir.

Bu kapsamda öncelikle eşitlik kavramı tarif edilerek; ulaşımda eşitliği sağlamada kullanılan önemli bir araç olan erişilebilirlik konusu aktarılacak; sonraki aşamada erişilebilirliğin Türkiye'de mekansal planlar yapım yönetmeliğinde hangi araçlarla tarif edildiğine dikkat çekilecektir. İkinci aşamada toplumun "dezavantajlı olarak kabul edilen grupları" tanımlanacak; üçüncü ve son aşamada ise toplumda dezavantajlı olarak tarif edilen kesimlerin kentsel hizmetlere erişilebilirliğini iyileştirmede ve dolayısıyla "dezavantajı" sıfatını ortadan kaldırabilmede önemli bir araç olan toplu taşıma sistemi ve uygulamaları üzerinde durulacaktır.

\section{Eşitlik Kavramı-Eşitliğin Sağlanmasında Mekansal Bir Araç Olarak Erişilebilirlik ve Mekansal Planlar Yapım Yönetmeliğindeki Karşılığı}

"Eşitlik, toplumdaki farklı grupların fırsat eşitliğine sahip olmalarını engelleyen çeşitli engelleri anlamak ve bunları ele almaktır." Bu cümle, Glasgow Şehir Meclisine aittir (www.glasgow.gov.uk den alıntılayan Ayhan, 2009, s.4551). Dolayısıyla "eşitlik" kavramı kişinin durduğu ve baktığı noktaya göre farklı anlamlar kazanabilecek ve çok boyutlu ele alınması gereken bir kavramdır.

Eşitliği; fayda ve maliyetlerin dağılımının adil ve uygun olup olmamasıyla ilişkilendiren Litman'a (2017) göre de; ulaşım planlama kararları çeşitli ve önemli eşitlik etkilerine sahiptir. Bu etkiler:

(1) Ulaşım kalitesinin insanların ekonomik ve sosyal fırsatlarını etkilemesi;

(2) Ulaşım işletmelerinin, aktivitelerinin ve hizmetlerinin; diğer kullanıcılar üzerinde "trafik sıkışıklı̆̆ı, kaza riski, kullanıcı ücretlerinden fonlanamayan altyapı maliyetleri, kirlilik ve istenmeyen arazi kullanım etkileri" gibi; dolaylı etkiler ve harici maliyetler oluşturması;

(3) Hanehalkı, iş ve hükümet giderlerince paylaşılan ulaşım giderleri oluşturması (iş adamları, toplumu oluşturan bireyler ve hükümete ek maliyetler getirmesi);

(4) Vergi desteği ve ulaşım haklarıyla ilgili önemli kamu kaynakları gerektiren ulaşım hizmetleri gerektirmesi, 
(5) Ulaşım planlama kararlarının gelişme yeri ve türünü ve bu nedenle de erişilebilirlik, arsa değerleri ve yerel ekonomik aktiviteleri etkilemesi ve

(6) Ulaşım planlama kararlarının işgücü ve ekonomik gelişmeleri etkilemesidir (Litman, 2017, s.50-65).

Dolayısıyla farklı arazi kullanım türleri arasında ulaşım ilişkilerinin nasıl kurgulandığı; bu hizmetlerin kullanıcısı olan insanların fayda ve maliyetlerden etkilenme derecelerini belirlemesi açısından önemlidir. Bu bağlamda erişilebilirlik kavramı ve herkes için erişilebilirliği yaymanın temel bir aracı olarak toplu taşıma hizmetlerinin kurgulanış biçimi ile planlama çalışmalarının öngördüğü fonksiyonların mekan üzerindeki dizilimi önem kazanmaktadır.

Toplumsal anlamda eşitlik unsurundan faydalanamayanlar "dezavantajlı olma durumuyla" tanımlanmaktadır. Ulaşım da eşitliği dağıtan bir unsur olarak "avantajlı olma durumunu dengelemesi açısından" önemlidir.

Avantajlı olma durumu ise kentsel hizmetlere erişilebilirliğin toplumun tüm kesimleri için benzer özelliklere sahip olması yani standardize edilmesi ile ortadan kaldırılacaktır. Hedef diğerlerine göre daha avantajlı olan kesimler oluşturmak değil; kentsel hizmetlere erişim konusunda mümkün olan en iyi koşullara sahip kesimler oluşturmak olmalıdır. Bu nedenle dengenin sağlanması "herkesin erişilebilirliğini mümkün kılan bir kent oluşturmak" üzerinden değerlendirilmelidir.

Mekansal planlar yapım yönetmeliğinin 12. maddesi; erişilebilirliği yürüme mesafeleri tarif ederek kontrol etmektedir. 12. maddenin 1 . bendinde "imar planlarında yürüme mesafelerinin; eğitim, sağlık ile yeşil alanların hizmet etki alanındaki nüfusun erişme mesafesi topoğrafya, yapılaşma, yoğunluk, mevcut doku, doğal ve yapay eşikler dikkate alınarak planlanır. Bu fikrada belirtilen hususların uygun olması durumunda ikinci ve üçüncü fikralardaki asgari yürüme mesafelerine uyulur." denilmektedir (Mekansal Planlar Yapım Yönetmeliği, R.G. 14.06.2014, Sayı: 29030, 2014).

Dolayısıyla yönetmeliğe göre; coğrafik özellikler açısından erişilebilirliğin sağlanmasında engeller ortaya çıkması durumunda; planlanan alanın özellikleri itibariyle yürüme mesafeleri yeniden planlanabilmektedir.

12. maddenin 2. bendinde ise; "imar planlarında; çocuk bahçesi, oyun alanı, açık semt spor alanı, aile sağlık merkezi, kreş, anaokulu ve ilkokul fonksiyonları takriben 500 metre, ortaokullar takriben 1.000 metre, liseler ise takriben 2.500 metre mesafe dikkate alınarak yaya olarak ulaşılması gereken hizmet etki alanında planlanabilir." denilmektedir (Mekansal Planlar Yapım Yönetmeliği, R.G. 14.06.2014, Sayı: 29030, 2014). 
12. maddenin 3. bendine göre ise 2 . bende benzer şekilde; imar planlarında; dini tesislerden küçük cami takriben 250 metre, orta (semt) cami takriben 400 metre mesafe dikkate alınarak yaya olarak ulaşılması gereken hizmet etki alanında planlanabilecektir. Mescitler ise yerleşik veya hareketli nüfusa göre takriben 150 metre hizmet etki alanında yapılabilecektir (Mekansal Planlar Yapım Yönetmeliği, R.G. 14.06.2014, Sayı: 29030, 2014).

Dolayısıyla yürüme mesafelerinin herkes için optimal mesafeler olup olmadığı tartışmaya açık olsa da; mekansal planlar yapım yönetmeliği; herhangi bir toplu taşıma hizmetine gerek kalmaksızın; çocuk bahçesi, oyun alanı, açık semt spor alanı, aile sağlık merkezi, kreş, anaokulu, ilkokul ve dini tesis gibi kentsel hizmet alanların "yürüyerek erişilebilir mesafelerde" planlamayı ilke edinmiş bir yönetmeliktir.

Yönetmeliğin 12. maddesi 4. bendinde ise; brüt nüfus yoğunluğunun 100 kişi/ha ve daha az olduğu yerleşim bölgelerinde, dağınık kırsal nitelikli yerleşmelerde veya yerleşik alanlarda uygun büyüklük ve nitelikte alan bulunamaması halinde veya bu fonksiyonlara ulaşımı zorlaştıran doğal ya da yapay eşikler olması durumunda; yürüme mesafelerinin artırılabileceği belirtilmiştir (Mekansal Planlar Yapım Yönetmeliği, R.G. 14.06.2014, Sayı: 29030, 2014).

Bu noktada kentsel hizmetlerin yürünebilir mesafelerde olmadığı durumlar için; toplu taşıma hizmetlerinin planlanması devreye girmektedir. Bununla birlikte; kentsel hizmetlerin yürünebilir olduğu noktalar için ise; dezavantajlı olmaları nedeniyle yürüyerek hizmetlerden faydalanmaları mümkün olmayan ya da yürüyerek ulaşmakta zorluk çeken toplumsal kesimlere yönelik olarak; "toplu taşıma sisteminin kurgulanış şekli" fırsat eşitliğinin sağlanmasında önemli bir kamu hizmeti olarak ortaya çıkmaktadır.

500 metre olarak kabul edilen yürüme mesafeleri; toplu taşıma duraklarının yerseçimine karar verilmesinde de kullanılan erişilebilirlik kriterlerinden biridir. 500 metrelik yarıçaplarda buffer zonelar oluşturularak toplu taşıma durağından hizmet alan ve almayan kentsel alanlar belirlenerek toplu taşıma durak noktaları planlanabildiği gibi; network analizleri ile doğrudan yol izleri üzerinden oluşturulan hizmet alanları incelenerek de; hizmet alanının d1şında kalan ve bu nedenle toplu taşımadan hizmet almayan noktalar belirlenerek öneri durak noktaları, aktarma noktaları ya da ara toplu taşıma seçenekleri belirlenmektedir.

Dolayısıyla mekansal planlar yapım yönetmeliği erişilebilirliğin ilk kademesini yürünebilir olma üzerinden tarif etmektedir. Yürünebilirliğin sağlanamadığı durumlarda ikinci kademe "toplu taşımadan hizmet alıyor 
olmak" olarak tarif edilebilir. Toplu taşımadan hizmet almak da kendi içerisinde hafif raylı sistem-otobüs-dolmuş gibi toplu taşıma türlerinden ara toplu taşımaya doğru kademelenen yapısıyla tarif edilebilir. Üçüncü kademe ise toplu taşımadan hizmet almayan kesimlerdir. Toplu taşımadan hizmet almayan kesimler aynı zamanda özel araç sahibi de değillerse; toplumun dezavantajlı kesimlerini oluştururlar.

\section{Toplumun "Dezavantajlı" Kesimleri}

Karl Marx'ın Kommünist Manifestosu'ndaki bir cümlesi (Attoh, 2016), insanların metropol kentleri inşa ettikten sonra; kırsal yaşamın sosyal kopukluğundan kurtulmuş olduklarını yazmaktadır (Marx ve Engels'den (1848) alıntılayan Attoh, (2016)). Ancak günümüzde metropol kentlerde izole edilme ve sınıf ayrımları daha da yaygin olmuştur.

İzleri mekansal anlamda da okunan dezavantajlı toplumsal kesimleri tarif etmek için farklı ülkeler farklı terimler kullanmışlardır. Birleşik Devletler'de getto, Fransa'da banliyö, İtalya'da quarteri periferici (dış mahalleler) ya da quarteri degradati (yoksul mahalleler), İsveç'te problemomrade (sorunlu bölgeler), Brezilya'da favela (teneke mahalleler), Arjantin'de villa miseria (sefalet mahalleleri) metropolü meydana getiren mekanların hiyerarşisinde en altta yeralan, adı kötüye çıkmış mahalleleri isimlendirmek için kullanılan özel terimlerdir (Wacquant, 2008, s.11).

Suç ve suçluluk kapsamında "sorunlu bölgeler", gelir düzeyi kapsamında yoksul mahalleler ya da dış mahalleler olarak tanımlanan bu mahalleler; genellikle gelir düzeyine bağlı olarak özel araç sahipliliği en düşük olan ve bu nedenle toplumun diğer kesimlerine göre toplu taşıma hizmetlerine bağımllığı en yüksek olan kesimlerdir. Toplu taşıma hizmetlerine olan yüksek bağımlılıkları nedeniyle de; yetersiz toplu taşıma hizmeti sunumu bağlamında; eğitim ve sağlık hizmetleri ile çalışma alanlarına erişim açısından da dezavantajlı grupları oluşturmaktadırlar.

Engelliler, yaşlılar, çocuklar, çocuklu anneler ve kadınlar "fırsat eşitliğinin sağlanması" anlamında farklı unsurlar dikkate alınarak değerlendirilmesi gereken toplumsal kesimi oluşturmakla birlikte; farklı etnik köken, ırksal yapı ya da uluslardan geliyor olmak da sosyal hizmetlere, barınma alanlarına ya da çalışma alanlarına erişim anlamında toplumun diğer kesimlerine göre dezavantajlı sayılabilecek toplumsal kesimlerdir. Bununla birlikte gelir düzeyi de fırsat eşitliği açısından avantaj ya da dezavantaj sağlayan ve toplumsal grupların ayrışmasında etkili olan değişkenlerdendir. 
Litman (2017) ise ulaşım konusundaki dezavantajlı toplumsal kesimleri düşük gelir grubunda olanlar, ehliyeti olmayanlar ya da araba sahibi olmayanlar, engelliler, dil problemi olanlar, erişimin mümkün olmadığı bir konumda olanlar (yalıtılmışlar), bakıcılar (bağımlı bir çocuğun ya da engelli bir yetişkinin bakımından sorumlu olanlar) ve yükümlüler (skklıkla sağlık hizmeti gereksinimi olanlar, okula gidenler veya işe gidenler) olarak tarif etmiştir.

Ulaşımda eşitlik, önemli bir vatandaşlık hakkı olup; engelli insanların bağımsızlığı ve kent hayatına ekonomik, sosyal ve politik katılımı kritik öneme sahiptir. Engelli insanların ödenebilir ve güvenli ulaşıma erişimini garanti altına almak için toplu taşıma desteklenerek daha fazla çaba sarfedilmelidir (AAPD, b.t., s.5).

American Association of People with Disabilities (AAPD) (b.t.); ödenebilir ve güvenilir ulaşım sayesinde; engellilerin eğitim, iş, sağlık, konut ve toplum hayatı gibi önemli fırsatlara erişilebilirliğinin mümkün kılındığını belirtmiştir. Ulaşım ve hareketlilik; engelli toplumlardaki vatandaşlık hakları ve fırsat eşitliği konularıyla mücadele etmenin anahtar rolü olarak gösterilmiştir. Çalışmada özellikle kırsal alanlarda yaşayan engellilerin işe gitmek, sağlık ve eğitim hizmetlerinden yararlanmak, konut alanlarına gitmek ve toplum hayatına katılmak için erişilebilir ve ödenebilir ulaşım seçeneklerine ihtiyaç duyduğu ifade edilmiştir (AAPD, b.t., s.5).

Bureau of Transportation Statistic' in araştırmasına göre; Amerika' da 15 milyon insan ulaşım hizmetlerine ulaşmakta güçlük çekmekte olup; bu insanların 6 milyonu engellidir. Bununla birlikte aynı araştırmaya göre; 3.5 milyondan fazla insan evlerini hiç terketmezken; bu insanların 1.9 milyonunun engelli olduğu ifade edilmiştir. Evinden hiç dışarı çıkmayan 560.000 engelli ise bunun nedenini ulaşım güçlükleri olarak ifade etmiştir (Issue Brief, 2003, s.1-2).

“Americans with disabilities act 1990'da (ADA); toplu taşıma sisteminde kullanılan tüm yeni taşıtların erişilebilir olması, zorunlu tutulmuştur. Bununla birlikte kilit noktalardaki mevcut demiryolu istasyonlarının, tüm yeni demiryolu istasyonlarının ve hizmetlerinin de erişilebilir olması zorunlu tutulmuştur. Toplu taşıma sistemini kullanamayan engelliler içinse toplu taşıma işletmelerinin kapıdan kapıya çalışan bir hizmet sağlamak zorunda olduğu belirtilmiştir. Bununla birlikte kırsal alanlardaki engellilere kentsel hizmetlere ulaşımda herhangi bir seçenek sunulmadığı da dikkat çekilen noktalar arasındadır. Erişilebilirliği sağlamak için tüm istasyonları erişilebilir yapmak gerektiği de dikkat çekilen başka bir konudur (AAPD, b.t., s.1-5).

Engelli insanların bir istasyon ya da otobüs durağına erişebilmek için; normal bir insandan daha fazla çaba sarfetmesi; bazı durumlarda yolculuktan 
vazgeçmesine neden olabilmektedir (AAPD, b.t., s.1-5). Bu engelleri aşmak için kullanılabilecek alternatiflerden biri de paratransit olup; daha çok kapıdan kapıya hizmet eden minibüslerle sağlanmaktadır (AAPD, b.t., s.1-5).

Araç alamayan ya da kullanamayan pek çok engelli ise taksi hizmetlerini tercih etmektedir. Toplu taşıma sistemlerinin kullanışsız ya da erişilemez olduğu bölgeler için; taksiler toplu taşıma sistemine göre daha büyük bir esneklik ve özgürlük sağlamaktadır. Bununla birlikte taksiler paratransitlere göre daha maliyet efektif yani daha ucuzdur. Bu nedenle toplu taşıma işletmelerinin engelli insanlara taksi hizmeti sağlayarak para tasarruf edebileceği de tartışılan konular arasındadır (AAPD, b.t., s.1-5).

Irk ve etnik yapı da; ulusal politikalar sonucu dezavantajıl kesimler ortaya çıkarabilmektedir. Tarihte ırkı ya da etnik kökeni nedeniyle ulaşım politikaları kullanılarak ötekileştirilmeye çalışılmış kesimler bulunduğu literatür taramaları sonucunda tespit edilmiştir.

Bunu destekler şekilde Hairston (2016) çalışmasında karayollarının başka renkteki topluluklarda kesintiye uğraması ya da tren güzergahlarını belli bir ırkın yoğunlaştığı yoksul alanlara gelmeden önce bitmesi gibi, ırksal ve ekonomik eşitsizlikleri güçlendirme ve abartma konusunda "Amerika'nın" ulaşım yatırımlarıyla ilgili uzun bir tarihi olduğundan bahsetmiştir (Hairston, 2016).

Dolayısıyla tarihsel süreçte karşılaşılan ve siyasi nedenlerle toplumun farklı etnikten, ırktan ya da ulustan gelenleri ayrıştırıcı politika örneklerinin aksine; toplu taşıma sistemine yönelik politikalar bütünleştirici yönde kullanılırsa; gelecekte toplum için suç vb. açlardan dezavantaj oluşturabilecek toplumsal kesimlerin kentsel hizmetlere ulaşımı ve dolayısıyla kentin gelecekteki ekonomik, sosyal, kültürel ve mekansal yaşantısının kalitesinin artttrılmasına olumlu yönde katkılar sağlanabilecektir.

\section{Eşitliğin Dağılımında Bir Araç Olarak Toplu Taşıma Sistemleri}

Lefebvre'ye (1968) göre şehir hakkı (right to the city) kentsel kaynaklara erişmekten daha çok merkeze ulaşmaktır. Yani şehrin kalbinde, sosyal aktivitelerin, ekonomik faaliyetlerin olduğu yerde olmaktır (Lefebvre, 1968).

Lefebvre'nin (1968) düşüncelerinin farklı bir yaklaşımını da Harvey (2008) vermektedir. Harvey'e (2008) göre şehir hakkı kentsel kaynaklara ulaşmaktan ziyade; şehri değiştirme ve kendimizi de değiştirme hakkıdır (Harvey, 2008, s.23-40). Yani toplumu oluşturan bireylerin; ulaşım sistemine adil erişiminin sağlanamamış ya da sağlanmamış olması; bireyin hareketliliğine engel olması nedeniyle bireyin şehri ve kendini değiştirme hakkının da elinden alınması anlamina gelmektedir. 
Hamburg, Blair ve Albright (1995) "mobility as a right" adlı çalışmalarında hareketliliğin temel bir hak olduğunu ifade etmişlerdir. Hareketlilik hakkının kamu planlama sürecinde garanti altına alınması gerektiğini belirttikleri çalışmalarında; altyapı yatırım stratejilerinin de herkes için hareketliliğe erişim sağlayacak şekilde sağlanması gerektiğini belirtmişlerdir (Hamburg, Blair ve Albright, 1995).

Hareketlilik birçok faktörden etkilenmekte olup; bunlar gelir durumu, yaşam alanı, coğrafik özellikler, özel araç sahipliliği, cinsiyet, yaş, sağlık durumu, kişinin sosyal ve ekonomik durumu vb.'dir.

Minneapolis ve St. Paul halen daha ulaşım karar verme süreçleriyle eşitliği oluşturmaya çalışan eyaletlerdir (Hairston, 2016). Yollar, köprüler, toplu taşıma, demiryolu ve diğer ulaşım sistemleri bizim yalnızca nasıl ulaşacağımıza ve nereye ulaşmamız gerektiğine değil; ne çeşit fırsatlara ulaşabileceğimize de karar vermektedir (işyerlerinden, çocuklarımızın katılabileceği okullara ve erişebileceğimiz kentsel hizmetlere) (Hairston, 2016).

Bunun yanı sıra toplu taşıma sistemlerinin geliştirilmesi, (1) kentsel yoksulluğa sahip çıkan bir belediyenin ön planda olması ve (2) kente ait strateji ve imar planlarında önemli rol alması ile mümkün olabilir (The World Bank, 2002). Başka bir deyişle, toplu taşıma, kentin yoksul bölgelerine demokrasi ve eşitlik getirmektedir. Bu yüzden bu sistemler ekonomik ve kâr amaciyla işleyen sistemler olarak değil; kamuya ait sistemler olarak planlanmalıdır (Rodriguez, Comtois ve Slack, 2006). Aslında, toplu taşıma sistemini yöneten grup, kimin topluma ait olup olmadığına karar vermiş olmaktadır (Attoh, 2016).

Bu düşünceyi destekler şekilde ABD Başkanı Johnson tarafından hazırlanması istenen ve 1968'de yayınlanan 'Tomorrow's Transportation' adlı rapora göre; toplu taşıma sistemleri, alt gelir grubu tarafından kullanılan ve geleceğin ulaşım sorunlarına çözüm olarak öngörülen sistemlerdir. Toplumda ulaşım hareketliliği düşük olan grupların (alt gelir grubu, ev hanımları, gençler, azınlıklar, yaşlılar ve engelliler) kullanabileceği ve bu gruplara eşitliği getirebilecek bir sistem olarak tanımlanmıştır. Düşük gelir grubuna mensup olan ve özel taşıtı olmayan işçi sınıfı, işyerlerinden, sosyal hizmet alanlarından ve sağlık hizmetlerinden mahrum bırakılmıştır. ABD Ulaşım Bakanlığı'na göre bu grupların ulaşım hareketliliğini ve ulaşım eşitliğini getirecek sistem, toplu taşıma sistemlerinin ve karayollarının uygun bileşimidir (Haar, Cole ve Merritt, 1968).

Rodriguez, Comtois ve Slack (2006) çalışmalarında toplu taşıma sistemlerinin şehir planlaması ve alan kullanımı açısından etkilerinin, üç farklı noktada birleştiğini ifade etmiştir. Bunlar: 
(1) ulaşabilirlik: yatırımın ve ekonomik aktivitelerin yerseçimi için önemlidir. Çalışanlar tarafından kolay ulaşılabilen alanlar, yatırımlar için daha mantıklıdır.

(2) yakınlaştırma/bir noktada birleştirme: ulaşım sistemi kapsamında planlanan güzergâhlar; kentteki bölgeleri ve fonksiyonları birbirine bağladığı için; planlanan ulaşım yatırımlarının etkisiyle; arazi kullanım durumunda da değişikliklere neden olabilmektedir. Toplu taşıma güzergâhlarına dahil olan alanlar diğer alanlara k1yasla daha değerlidir.

(3) entegrasyon: toplu taşıma sistemleri farklı arazi kullanım türüne sahip alanları birleştirmekte ve verimliliği arttırmaktadır (Rodriguez, Comtois ve Slack, 2006).

Weisbrod ve Reno'nun (2009) raporunda da toplu taşımanın olumlu etkilerinden bahsedilmiştir. Toplu taşıma yatırımları, dolaylı ya da dolaysız olarak iş alanları sağlamakta ve kentin ekonomisini canlandırmaktadır (Weisbrod ve Reno, 2009, s.1-77).

Toplu taşımanın ev-iş mesafesini kısalttığı, trafik problemlerine alternatif sağladığı, ucuz ulaşım alternatifi sunduğu için kentin ekonomisine olumlu etkisi olduğu belirtilmiştir (Weisbrod ve Reno, 2009, s.1-77). Bu yüzden toplu taşıma sistemlerinin kamusal olması ve akıla ve sürdürülebilir bir şekilde planlanması çok önemlidir.

Bununla birlikte Bannister (1995) çalışmasında toplu taşımanın yüksek kaliteli bir yaşam sürdürebilmek ve yüksek derecede ulaşılabilirlik için bir araç olduğunu ifade etmiştir.

Rodriguez, Comtois ve Slack (2006) toplu taşıma sistemlerinden ve onun öneminden bahsettikleri çalışmalarında bu sistemlerin görevinin toplum için şehrin değişik noktalarına ulaşabilmek olduğundan bahsetmiştir. Toplu taşıma sistemlerinin en önemli özellikleri (1) esnek olması, (2) sıklığı, (3) maliyeti ve (4) toplu taşıma durakları arasındaki mesafedir.

Toplu taşıma kamusal bir hizmet olup; toplumsal eşitliği sağlamak için kullanılabilecek bir araçtır. Kamusal bir hizmet olması nedeniyle kar odaklı olmamalıdır (Rodriguez, Comtois ve Slack, 2006).

Araştırmalarını New York'ta sürdüren Attoh (2016) çalışmasında, "toplu taşıma sistemleri, topluma ait olup olmadığımıza karar veren sistemlerdir" demiştir. Dolayısıyla; Rodriguez, Comtois ve Slack (2006) ile aynı düşüncede olup, toplu taşıma sistemlerinin kamusal bir hizmet programı olduğunu da ifade etmiştir (Attoh, 2016). 
Shlomo (2016) çalışmasında toplu taşımanın yoksul ve azınlıkta olan sınıflar için ne kadar önemli olduğunu ve yerel yönetim politikaları açısından belediyelerin bu anlamdaki rolünün önemi vurgulanmıştır.

İnsanların toplu taşıma sistemine erişebilir olmasının; iyi okullara da daha kolay erişmelerini sağlamasından ve dolayısıyla yüksek eğitim alma şansına sahip olmalarından, bölge için daha nitelikli bir işgücünün "bu şekilde geliştiğinden" bahseden Blackwell (2017) ise; sağlık hizmetlerine daha kolay ulaşan insanların; daha fazla koruyucu bakıma ve daha düşük sağlık maliyetlerine hizmet ettiğini ifade etmiş̧ir. Bununla birlikte toplu taşıma sistemleri suç oranlarını da düşürmekte olup; daha fazla toplu taşıma; fırsatlara daha kolay erişimi mümkün kılmaktadır (Blackwell (2017)).

Ulaşımı gelir eşitsizliğiyle mücadele biçimlerinden biri olarak ele alan ve güvenli ve yeterli ulaşım eksikliğinin; düşük gelir grubundaki insanların kendileri ve çocukları için daha iyi hayatlar inşa etmelerinde engel oluşturduğunu ifade eden Henderson ve Blackwell (2015); ulaşımdaki uzun dönemli politikaların; ekonomik firsatları arttırmada ve yoksulluğu azaltmada önemli bir paya sahip olduğunu ifade etmişlerdir (Henderson ve Blackwell; 2015).

Henderson ve Blackwell'e (2015) göre; ulaşım bizi sadece işe ve ekonomik fırsatlara değil; kaliteli konuta, okula ve sağlık bakımına ulaştıran bir role sahiptir. Bununla birlikte adil ulaşım politikaları; ekonomik hareketlilikle baş etme şansına sahiptir ve toplumdaki herkesin yerel ekonomiye katılımını ve yerel ekonomiden faydalanmasinı garanti etmektedir (Henderson ve Blackwell; 2015).

Toplu taşıma ve kentsel eşitsizlikler hakkında yapılan çalışmalarda;

- Ulusal ve yerel ölçekte ulaşım ve toplu taşıma politikaları tartışılmiş,

- Toplu taşıma hizmetini geliştiren ilgililerin kamu ya da özel teşebbüs olması ve bunun sonuçları değerlendirilmiş,

- Dezavantajlı gruplara yönelik toplu taşıma uygulamaları incelenerek değerlendirilmiş,

- Kent makroformu ya da kentsel yoğunluk dağılımı çerçevesinde toplu taşıma sistemleri değerlendirilmiş,

- Toplu taşıma hizmetlerinin adil dağılıp dağılmadığı incelenmiş ve bu amaçla yöntem geliştirme çalışmalarında bulunulmuş,

- Toplu taşıma hizmetlerinin işgücüne katılım oranı üzerindeki etkisi incelenmiş, 


\section{- Ve son olarak erişilebilirlik konusu kentsel tasarım ölçeğinde ince- lenmiştir.}

\section{Ele alış şekli itibariyle araştırmalar arasında ölçek farkları olsa da; birbirini tamamlayıcı nitelikte olan çalışmalar genel olarak aşağıdaki gibi özetlenebilir:}

Dezavantajlı
Gruplar ve
Toplu Taşıma
Politikaları

- Attoh (2016); Amerika'nın Syracuse, NY kentinde engelli yolcular için yapılan yeniliklerde ne kadar kamu yararı olduğunu tartışmış ve toplu taşıma politikalarını incelemiştir (Attoh, 2016);

- Shlomo (2016) etnik olarak çok karışık olan İsrail'in Kudüs kenti için Palestinlerin yaşadığı mahallelerde toplu taşıma sistemiyle nasıl bir değişim yaratıldığını incelenmiştir;

- Blackwell (2017); çalışmasında curb-cut effectten bahsetmiş ve; eşitliği herkesin otobüsle seyahat etme hakkı olması olarak açıklamış; adaleti ise tekerlekli sandalyeli insanların; kaldırımlardaki açıklıklar sayesinde otobüs duraklarına ve otobüs hatlarına ulaşarak istedikleri yerlere gitmesi olarak tanımlamıştır. Bununla birlikte; Curb-cut effect' in Amerikan caddelerinde yeni bir gelişmenin kaynağı olduğunu ve bunun sonucunda "korunaklı bisiklet yollarına kavuşulduğunu" ifade etmiştir (Blackwell; 2017).

\section{Toplu taşıma sistemi Hizmet Farkları}

\section{Mamun (2011) New Haven kentinin toplu taşıma sistemindeki} hizmet farklarını incelenmiştir (Mamun, 2011);
Toplu taşıma ve işgücüne katılım oranı
Chatman ve Noland (2013), Toplu taşıma sisteminin işgücüne katılım oranındaki etkisiyle ilgili olarak metro alanlarına eklenen bir kaç otobüs ya da tren koltuğunun (her 1000 kişi için 4 tane), her mil kare merkezi alanda çallşan sayısını 320 kat arttırdığını ve bu durumun "gizli ekonomik değer" olarak tanımlandığını belirtmiştir,
Yol Hakk1-

Çevre Hakkı
- $\quad$ AAPD'de (b.t.: 4). Güvenli ve erişilebilir yol hakkının; toplum hayatının önemli elementlerinden olup; yol hakkı ifadesiyle caddeler, kaldırımlar, yaya geçitleri, kaldırım kenarı rampaları, geçiş sinyalizasyonu, yol üstü park alanları ve diğer kamu yatırımlarının tanımlandığı belirtilmiştir. Dolayısıyla farklı bölgelerin adil bir şekilde birbirine bağlanmasının yalnızca taşıt değil; yaya yollarının da kademeli olarak, akılcı bir şekilde planlanmasıyla mümkün olduğunun ifade edilmesi;

- Chakraborty, (2006: 315-323); ulaşım projelerinin çevre hakkı sonuçlarını değerlendirebilmek için; niceliksel gösterge seti geliştirmeye odaklanmış ve ulaşım sistemindeki değişikliklerin olumsuz etkilerini değerlendirebilmek ve toplumun dezavantajlı kesimlerinin orantısız (adil olmayacak şekilde) etkilenip etkilenmediğini belirlemek için ve ulaşım plancılara kendi etki değerlendirme metodolojileri içerisinde çevre haklarını (EJ:environmental justice) göz önüne almalarında yardımcı olmak için uygulanabilir gösterge ve araçlar gerektiğinden bahsetmiştir
Coğrafik eşitlik analizleri
Karner (2016: 46-54) coğrafik eşitlik analizlerinin farklı mekansal birimlerin performansını karşılaştırdığını belirten çalışmasında, coğrafik ve sosyal eşitliği anlamak için bazı niteliksel ve niceliksel değerlendirmelerde bulunmanın gerektiğinden bahsetmiş ve bunlardan en popülerlerini erişilebilirlik, yolculuk süresi, yatırımların parasal değeri ve hava kalitesi olarak ifade etmiştir. 
Yolculuk SüresiEkonomik BüyümeSosyal Hareketlilik Çıtası
Henderson ve Blackwell (2015) yolculuk süresi ile bir ailenin ekonomik açdan büyümesi ve sosyal hareketlilik çıtasının yükseltilmesi arasında ilişki kurmuş; kısa yolculuk süresine sahip alanlarda yaşayan ailelerin ekonomik çıtalarını yükseltmede uzun yolculuk süresine sahip alanlardan daha iyi olduğunu ve bununla birlikte yolculuk süresinin sosyal hareketlilik çıtasını yükseltmede önemli bir kestirim aracı olduğunu belirtmiştir
Kent Makroformu Kentsel Yoğunluk ve Toplu taşıma sistemi kullanım oranlar1
Newman ve Kentworthy (1989a-b) kent makroformu ve kentsel yoğunluğa bağlı olarak toplu taşıma sistemlerinin kullanım oranlarını incelenmiştir. Avrupa'daki şehirlerde özel araç sahipliliğine kıyasla yüksek oranlarda kullanılan kentsel toplu taşıma sistemlerini; kent dokusunun daha yoğun (geniş alanlara yayılmamış) olmasıyla ilişkilendiren Newman ve Kentworthy (1989a-b); bunun aksine Amerika ve Avustralya'daki şehirlerde toplu taşıma sistemlerinin kentsel ulaşımdaki oranının daha az olmasının nedenini bu ülkelerin daha geniş coğrafyalara sahip olmalarına bağlamıştır.

\section{Tartışma ve Sonuç}

Ulaşım; hareketlilik, ulaşılabilirlik, ulaşabilirlik, toplumsal eşitlik ve devamında eşitlik için çabalayan; ulaşım politikaları ile beraber gelişen bir sistemdir. Özellikle metropollerde yaşayan insanlar için ulaşabilirlik ve hareketlilik; sosyal yaşam için kritik öneme sahiptir. İnsanların hareketliliği kendi sosyal ve ekonomik statülerine göre değişmektedir. Bu durum kentte yaşayan toplum için de büyük bir ayrışmayı getirmektedir. Toplumun ekonomik açıdan dezavantajlı kesimleri kent yaşantısına yeterince katılamamakta; dolayısıyla fırsat eşitliğine sahip olamamaktadır.

Bununla birlikte; toplu taşıma sistemleri sadece alt gelir grubunun ulaşım sistemi olarak görülmemelidir. Bunun örneği Avrupa'daki sistemler olup; toplu taşıma politikaları ve yatırım kararlarıyla trafiğin azaltılması sonucu kent sağlığına büyük ölçüde fayda sağlanmaktadır.

Toplu taşıma sistemlerinin tüm yolculuklar içerisindeki payının artması aynı zamanda trafik problemlerine de alternatif bir çözümdür. Son dönemde basında sıklıkla yer alan ve dizel araçların insan sağlığı üzerindeki olumsuz etkilerine yönelik farklı ülkelerin emisyon önleme çalışmalarına ilişkin haberler, hava kirliliğini azaltmaya yönelik Çin'de trafiğe çıan araç sayısını azaltma ya da yasaklama politikaları, yola belirli bir mesafeden daha yakında oturan insanlarla Alzheimer vb. hastalıkların ilişkilendirilmesi temiz ulaşım sistemlerine ve bu kapsamda da toplu taşıma sistemlerine yönelinmesi gerektiğinin bir göstergesidir.

Hareketliliğin seviyesi ve ulaşımın kalitesi, bölgenin ekonomisini ve dolayısıyla insanların yaşam kalitesini belirlemektedir. Kentte yaşayanlar için 
kentteki ulaşım sorunları (trafik, uzun seyahatler, aktarma vb.) günlük hayatı olumsuz etkileyen faktörlerdir.

İnsanların, malların ve bilginin mekândaki hareketleri her zaman toplulukların ortak bileşenleri olmuştur. Kentler için ulaşım sistemlerinin geliştirilmesi ve hareketliliğin arttırılması, toplumu oluşturan bireylerin fırsatlardan eşit yararlanmasını sağlamanın yanısıra; kent ekonomisinin gelişmesini ve kentin küresel ekonomiye katılmasını sağlamaktadır.

Ulaşımın toplumsal açıdan en önemli rolü toplumun her kesimi için eşit oranda hareketlilik farkını azaltması; dolayısıyla toplumu oluşturan bireylerin ekonomik, sosyal, kültürel, politik ya da mekânsal farklılıklarını gözardı ederek; yaşlı, çocuk, engelli vb. hangi toplumsal gruba ait olursa olsun homojen bir hareketliliğe sahip olmasını sağlayacak koşulları oluşturması demektir. Bu azaltma da ancak çevreci ve sürdürülebilirliğe önem veren kentsel ulaşım politikaları ile kazanılabilir.

Bir planlama süreci her topluluğun eşitlik kaygılarını ve önceliklerini yansıtmalı ve böylece kamusal ilişkiler ulaşımın adil planlanmasında önemli rol almalıdır (Litman, 2017, s.50-65). Dolayısıyla çok disiplinli bir eylem alanı olan planlama çalışmaları gerçekleştirilmeden önce; çalışmaya esas oluşturacak analizlerin yapılması için gerekli veri toplama aşamasında; mekanın kullanıcılarına sorulacak sorular ve tespit edilecek ekonomik, demografik, kültürel, sosyal ve mekânsal özelliklerin titizlikle belirlenmesi ve tüm uygulamaların ayrıştırıcı değil, bütünleştirici bir şekilde toplumun her kesimi için, her kesimin ihtiyaçlarını da göz önüne alacak şekilde sürdürülmesi; mekanın ve ulaşımın adil planlanmasındaki başarı oranını arttırması açısından önemlidir.

Şehir ve ulaşım plancıların; konut ve çalışma alanları arasında bağlantı kuracak ulaşım kademelerine ve güzergahlarına ilişkin verdikleri kararlar; sözkonusu ulaşım güzergahları üzerinde yer alan arsaların imar beklentisinin de etkisiyle değer kazanmasına neden olmaktadır. İmar baskısının önüne geçilememesi ve bazı durumlarda planlama çalışmalarına aykırı, plan dışı gelişmelerin meydana gelmesi sonucu; ulaşım planlama kararlarının revizyonuna ihtiyaç duyulmakta; bu durum ulaşımın adil dağılımına yönelik yapılan çalışmaları amacına ulaşamadan atıl duruma getirmektedir.

Plan ve politikaların sürdürülebilirliği bu nedenle büyük önem taşımaktadır. Dolayısıyla Henderson ve Blackwell'in (2015) de belirttiği gibi uzun dönemli ulaşım politikaları; ekonomik fursatları arttırmada ve yoksulluğu azaltmada önemli bir paya sahiptir. 
Toplu taşıma sisteminin her bölgeye eşdeğer hizmet etmesi ve toplu taşıma sisteminin ulaştırılamadığı ya da ulaşımının ekonomik olmadığı durumlarda toplu taşıma sisteminin yerini alabilecek ara toplu taşıma, taksi ya da paratransit gibi alternatif çözümler geliştirilmesi; planlama bölgelerinin ulaşım hakkını gözetmesi için başvurulabilecek araçlardır.

Özel araç almanın bir tercih olmaktan çıktığı alt gelir grubu için; toplu taşıma sistemine kolay erişebilir olmak büyük önem taşımaktadır. Dolayısıyla alt gelir grubunu odağına alan bir şehirde toplu taşıma sisteminin planlanmasında "yerel yönetimlerin başarısı" büyük önem taşımaktadır.

Toplu taşıma sisteminden hizmet almayan bölgeler; bu alanlarda yaşayan insanlarda dışlanmışlık duygusu, aidiyet hissetmeme ya da topluma ait olmama duygusu oluşturmaktadır. Toplu taşıma sisteminden hizmet almayan bölgeler; kullanıcıları açısından farklı sorunlar meydana getirse de; burada yaşayan bireylerin kent ekonomisine katılamamasl; eğitim, sağlık vb. hizmetlerden rahatlıkla faydalanamaması vb. nedenler; belki de bu alanları gelecekte suç alanları haline getirecektir.

Bu bakımdan Attoh'un (2016) sözü anlam kazanmaktadır: "Toplu taşıma sistemleri, topluma ait olup olmadığımıza karar veren sistemlerdir". Bununla birlikte Henderson ve Blackwell (2015) "güvenli ve yeterli ulaşım eksikliğinin; düşük gelir grubundaki insanların kendileri ve çocukları için daha iyi hayatlar inşa etmelerinde engel oluşturduğunu ifade etmişlerdir".

Toplu taşıma; toplumsal eşitliği sağlamada önemli etkisi olan bir araç olma özelliği nedeniyle ve alt gelirden üst gelire; toplumun her kesiminin toplu taşıma sistemi sayesinde her türlü hizmeti alabilmesinin sağlanması nedeniyle (toplumu besleyen bir öğe olması nedeniyle); Rodriguez, Comtois ve Slack'in (2006) de ifade ettiği gibi; kar amaçlı olmamalıdır. Henderson ve Blackwell'de (2015) çalışmasında benzer şekilde ulaşımın gelir eşitsizliğiyle mücadele biçimlerinden biri olmasına rağmen hakettiği önemi görmediğine vurgu yapmiştır.

Chakraborty (2006); ulaşım planlama sürecinde çevre haklarına ilişkin ilkelerin geliştirilmesi ve ulaşım projelerinin orantısız etkilerinin değerlendirilebilmesi için az sayıda rehber çalışma olduğundan bahsetmiştir. Bununla birlikte ulaşım plancıların ulaşım sistemindeki değişikliklerin dağıtımsal etkilerini değerlendirmeleri için bir metod ve prosedür geliştirilmesi gerektiğini de ifade etmiştir. Karner'da (2016) çalışmasında Chakraborty'e benzer şekilde coğrafik ve sosyal eşitliği anlamak için bazı niteliksel ve niceliksel değerlendirmelerde bulunmak gerektiğinden bahsetmiştir. Türkiye'de de bu konuda rehberlik edecek nitelikli çalışmalara ihtiyaç duyulmaktadır. 
Harvardlı araştırmacılar; kısa yolculuk süresine sahip alanlarda yaşayan ailelerin ekonomik çıtalarını yükseltmede uzun yolculuk süresine sahip alanlardan daha başarılı olduğu sonucuna ulaşmışlardır. Bununla birlikte yolculuk süresi sosyal hareketlilik çıtasını da yükseltmekte önemli bir kestirim aracıdır (Henderson ve Blackwell (2015). Dolayısıyla; kent makroformu genişleyip yayıldıkça; kentsel bölgelere hizmet eden ticaret alanları ve diğer hizmetlerin dengeli bir şekilde dağılımı; tek merkezli kentlerden çok merkezli kentlere geçiş; beraberinde bu hizmetler arasında kurulacak güçlü ulaşım bağlantılarını gerektirmektedir. Bu durumun mümkün olmadığı geniş alanlara yayılmış kentler; daha kompakt yerleşmelere kıyasla dezavantajlı durumda kalmaktadır.

Toplu taşıma sistemlerinin dengeli dağılımı; toplumsal eşitliği sağlayan bir araçtır. Çünkü herkes özel araca sahip olacak ekonomik güçte ya da istekte değildir. Bununla birlikte; çeşitli engeller nedeniyle; insanların tek başlarına erişemeyecekleri hizmetler ya da kentsel alanlar da bulunmaktadır.

Bu noktada yerel yönetimlerin devreye girmesi ve çeşitli politikalar ortaya koyarak toplumun her kesiminin adil bir şekilde ulaşım hizmetlerinden yararlanabileceği ortamların oluşturulması gerekmektedir.

Yerel yönetimler tercih ettiği politikalarla; farklı toplumsal kesimlerin erişilebilirlik/ulaşılabilirlik düzeyleri arasındaki farkı kapatabilir (BRT sistemleri, raylı sistemler, akıllı kartlar, fiyat politikaları, planlamada toplu taşımanın öncülüğü, tasarım vb.).

Ancak farklı coğrafyalar için çözümler de farklılaşmaktadır. Gelişmiş ülkelerin toplu taşıma sistemleri genellikle raylı sistemlere dayalı, sürdürülebilir ve çevre dostu sistemlerdir. Bununla birlikte; sadece alt gelir grubu tarafindan kullanılmamakta; toplumun her kesimine hitabetmektedir.

Avrupa Birliği ülkelerinde; ulaşım politikalarından yola çıkılarak toplu taşıma sistemlerinin ne kadar önemli olduğu ortadadır. Ancak geniş kentsel alanlara sahip ve özel araç sahipliliğinin yüksek olduğu Amerika, Avustralya gibi gelişmiş ülkelerde, toplu taşımanın önemi azalmaktadır.

Çin ve Türkiye gibi ekonomisi büyümekte olan ve metropol kentleri bulunan gelişmekte olan ülkeler ise; toplu taşıma sistemlerini en son teknolojiyi kullanarak büyütmekte ve genel olarak raylı sisteme dayalı bir sistem kurgulamaktadır. Bu metropollerin tercih ettikleri toplu taşıma politikaları çok büyük önem taşımakta olup; kentlerin geleceği toplu taşıma sistemine yönelik tercih ettikleri politikalarla yüksek derecede ilişkilidir.

Diğer taraftan bir toplumda; özel araç kullanıcılarının yolculuklarında özel araçlarını kullanma konusundaki ısrarcı tutumları; kamusal bir hizmet 
olan toplu taşıma hizmetinin herkesi kapsayan bir uygulama politikasına sahip olmadığınının bir göstergesidir. Toplu taşıma politikaları özel araç sahiplerini kapsayamamakta; hatta bazı ekonomik kaygılarla içten içe desteklemektedir.

Toplumun dezavantajlı olarak tarif edilen kesimleri; herhangi bir ekonomik, sosyal, kültürel ya da demografik ayrıştırmaya gidilmeksizin; yolculuklarında toplu taşıma hizmetine mecbur olan ve bu nedenle de "özel araç sahibi olmayan herkes" olarak algılanmalı ancak toplu taşıma politikaları düzenlenirken; özel araç sahiplerini de kapsayıc olacak şekilde; toplam yolculuklar içerisinde özel araç kullanımındaki payın toplu taşıma hanesine kaydırılarak düşürülmesi; temel hedef olmalıdır.

Toplam yolculuklar içerisindeki özel araç kullanımının, toplu taşıma hanesine kaydedilerek düşürülmesi; herkesin kentsel hizmetlere ve dolayısıyla firsatlara erişimi konusunda bir iyileştirmeye gidildiğinin ve dolayısıyla hizmetlere erişilebilirlik anlamında yatay düzlemde bir gelişme kaydedildiğinin önemli bir göstergesi olacaktır.

Sonuç olarak ulaşım hakkından daha fazla bahsedebileceğimiz, daha adil, daha erişilebilir mekânsal planlama çalışmalarının gerçekleştirilebilmesi için;

(1) Planlama çalışması yapacakları kentin/kırın ya da kentsel/kırsal bölgenin kullanıcılarına ilişkin; hangi konularda fırsat eşitliğine ihtiyaç duyacaklarını tespit edebilmek amacıyla önceden bilgi toplamak;

(2) Kentte bu konuda özellikle oluşmuş dezavantajlı bölgeler varsa; bölgelerin özelliklerine bağlı olarak yapılabilecekleri tespit etmek ve planlara yansitmak;

(3) Kullanıcıların yalnızca oturdukları alanda kalmayacaklarını ve kent içerisinde hareket edeceklerini ve bunun en temel hakları olduğunu bilerek; tüm planlama alanında ulaşım hakkından yararlanmayı maksimize edecek asgari standartlar geliştirmek;

(4) Özel araç sahipliliğini desteklemektense; toplu taşıma sistemini merkeze alan ve bununla birlikte kademe kademe her bölgenin ihtiyacına uygun ulaşım türüne yönelik politikalar ve mekânsal tasarımlar oluşturmak;

(5) Tüm bu süreçte yönetim kademelerinin şehir ve ulaşım plancılardan oluşan ekibin bilimselliğine güvenerek destek olması; kentlerin sosyal, ekonomik, demografik, kültürel ve mekansal gelişimi ve gelecekteki kent yaşantısının kalitesinin arttırılması açısından yapılabilecek önerilerdir. 


\section{Extended Abstract}

\section{Equity, Accessibility and Public Transportation}

\author{
Richard Szeri \\ FlixMobility
}

\author{
İrem Ayhan Selçuk \\ Dokuz Eylül University
}

Equality is to understand and address various barriers that prevent different groups in the society from having equal opportunities (cited from www.glasgow.gov.uk by Ayhan, A., 2009, s.45-51). Therefore, the concept of equality is a concept that can acquire different meanings according to the point where the person stands and needs to be dealt with in multidimensional way.

Those who cannot benefit from social equality are defined as disadvantaged people. As an element of equality, transportation is also important in terms of balancing the status of being advantage.

State of being an advantaged person will be eliminated by standardizing accessibility to urban services. Target will be creating segments with the best possible conditions for access to urban services, rather than creating segments that are more advantageous than others. For this reason, the balance should be evaluated through creating a city that makes accessibility possible for everyone.

Different countries have used different terms to describe disadvantaged social groups whose traces are also read spatially. Ghetto in the United States, commuter in France, quarteri periferici or quarteri degradati in Italy, problemomrade in Sweden, favela in Brazil, villa miseria in Argentina are the special terms used to define neighborhoods that are at the bottom of the hierarchy of spaces that make up the metropolis (Wacquant, 2008, s.11).

These areas are defined as problematic areas within the scope of crime and guilt, poor neighborhoods or external neighborhoods within the scope of income level are generally the least dependent on private vehicles and therefore has the highest dependence on public transport services compared to other segments of the society. Due to the high dependence on public transport services; in the context of inadequate public transport service provision; they also constitute disadvantaged groups in terms of access to education and health services and working areas. 
The disabled, the elderly, children, mothers with children and women constitute the social segment that needs to be evaluated by considering different elements in terms of "equal opportunities" and coming from different ethnic backgrounds, racial structures or nationalities are social sectors that can be considered disadvantageous in terms of access to social services, housing or working areas. However, income level is one of the variable that provides advantages or disadvantages in terms of equality of opportunity and is effective in the segregation of social groups.

According to Lefebvre (1968), the right to the city is to reach the center rather than access to urban resources. That is to be in the heart of the city, where social activities and economic activities take place (Lefebvre, 1968). According to Harvey (2008), the right to the city, rather than access to urban resources; the right to change the city and to change ourselves (Harvey, 2008, s.23-40). In other words; lack of fair access to the transport system means that the right to change the city and the individual is taken away from the individual because of impedes the mobility of the individual.

In addition, Bannister (1995) stated that public transport is a tool for sustaining a high quality life and a high level of accessibility. Rodriguez, Comtois and Slack (2006) mentioned that public transportation systems and their importance in their work is to reach different points of the city for society. Public transport is a public service; and is a tool for providing social equality. So it should not be profit oriented due to being a public service (Rodriguez, Comtois and Slack, 2006).

Attoh (2016), who continues his research in New York, said that public transport systems are the systems that determine whether we belong to the society. Blackwell (2017) states that people have access to the public transport system; have better access to good schools and therefore, they have the chance to have higher education and more qualified workforce develops for the region in this way.

Henderson and Blackwell (2015) stated that addressing transport as one of the forms of combating income inequality and the lack of safe and adequate transport. In addition this; low-income people have barriers to building better lives for themselves and their children because of this they describe long-term transport policies; as an important tool for increasing economic opportunities and reducing poverty (Henderson and Blackwell; 2015).

According to Henderson and Blackwell (2015); transport has a role not only get us hire and economic opportunities; also quality housing, school and health care. However, fair transport policies; has the chance to cope with economic 
mobility and ensure that everyone in the community can participate in and benefit from the local economy (Henderson and Blackwell; 2015).

The literature on urban inequalities and public transport can be summarized as follows:

- Studies discussing national and local transportation and public transport policies;

- Studies discussing the role of public or private enterprises in improving public transport services;

- Studies examining public transport practices for disadvantaged groups

- Studies on public transport systems within the framework of urban macroform and urban density distribution

- Studies discussing the issue of developing methods for fair distribution of public transport services

- Studies evaluating the effect of public transport services on labor force participation rate

- Finally, studies examining accessibility on urban design scale.

The most important social role of transportation is to reduce the mobility gap equally for all segments of society; thus ignoring the economic, social, cultural, political or spatial differences of individuals who make up the society such as elderly, children, disabled etc. This reduction can only be achieved through urban transport policies that attach importance to environmental and sustainability.

Harvard researchers; concluded that families living in areas with short journey times were more successful in raising economic barriers than those with long journeys. However, travel time is an important predictive tool in raising the bar for social mobility (Henderson and Blackwell, 2015). Therefore; as the urban macroform expands and spreads; a balanced distribution of trade areas and other services serving urban areas; transition from monocenter to multicenter; requires strong transport links between these services. Cities spread over large areas where this is not possible; remains at a disadvantage situation compared to more compact settlements.

As a result, in order to realize more fair, more accessible spatial planning studies, which we can talk more about the right of transportation;

(1) Planners should gather information in advance to determine issues they need to settle equality of opportunity;

(2) Identify if there are areas that have no advantages compared to other segments of society and reflecting them on the plans; 
(3) Developing minimum standards to maximize the enjoyment of the right to transport system in the entire planning area;

(4) Rather than supporting private vehicle ownership; develop policies and spatial designs for the public transport system and, in turn, gradually meets the needs of each region;

(5) In this process, the management levels has to rely on the scientificness of the team of city planners and transport planners;

(6) are tools for the social, economic, demographic, cultural and spatial development of cities and the quality of future urban life.

This study is supporting by 2017.KB.FEN.2016 Dokuz Eylül University Rektorship, Department of Scientific Research Project (BAP) and same time; is the product of an incomplete master's thesis of The Graduate School of Natural and Applied Sciences.

\section{Kaynakça/References}

American Association of People With Disabilities (AAPD) (b.t.). Equity in transportation for people with disabilities. The Leadership Conference Education Fund, içinde 1-5. http://www.civilrightsdocs.info/pdf/transportation/final-transportation-equity-disability.pdf adresinden erişilmiştir.

Attoh, K. (2016). Public transportation and the idiocy of urban life. University of New York. Ayhan, A. (2009). Eşitlik ilkesi ve tarihçesi eşitlik ilkesi ve tarihçesi Türkiye'de kadın erkek eşitliği ve eşitsizliği. Hukuk Gündemi-II, 45-51. http://www.ankarabarosu.org.tr/siteler/ankarabarosu/hgdmakale/2009-3/8.pdf adresinden erişilmiştir.(www.glasgow.gov.uk'den alıntılanmıştır).

Bannister, D. (1995). Transport and urban development. E\&FN Spon publication: London.

Blackwell, A.G. (2017). The curb-cut effect. Stanford Social Innovation Review. https://ssir.org/articles/entry/the_curb_cut_effect, adresinden erişilmiştir.

Chakraborty, J. (2006). Evaluating the environmental justice impacts of transportation improvement projects in the US. Transportation Research Part D: Transport and Environment, 11(5), 315-323.

Chatman, D., G. ve Noland, R., B. (2013). Transit service, physical agglomeration, and productivity in US metropolitan areas. Annual meeting of the transportation research board, 1-22.

Haar, C. M., Cole, L. M. ve Merritt, H. W. (1968). Tomorrow's transportation. New systems for the urban future. US Department of Housing and Urban Development. Washington, D.C.

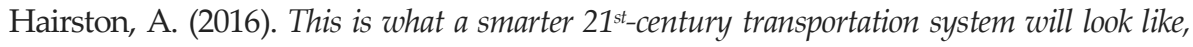
next city, op-ed, may 16-2016. https://nextcity.org/daily/entry/smart-21st-centurytransportation-system-op-ed-infrastructure-week adresinden erişilmiştir.

Hamburg, J., Blair, L. ve Albright, D. (1995). Mobility as a right. Transportation Research Record 1499, içinde (s.52-55). Transportation Research Board www.trb.org 
,file:///C:/Users/kullanici/Desktop/okunacakmakaleler/transportation\%20equityanalysis/1499-008.pdf_adresinden erişilmiştir.

Harvey, D. (2008). The right to the city. The New Left Review, 53, 23-40.

Henderson, W. ve Blackwell, A.G. (2015). How better transportation can fight income inequality. http://hehill.com/blogs/congress-blog/economy-budget/244832-how-bettertransportation-can-fight-income-inequality adresinden erişilmiştir.

Issue Brief (2003). Transportation difficulties keep over half a million disabled at home, no.3, Bureau of Transportation Statistics, US Department of Transportation, 1-2.

Karner, A. (2016). Planning for transportation equity in small regions: Towards meaningful performance assessment. Transport Policy, 52, 46-54.

Lefebvre, H. (1996 [1968]). Writings on cities: Henri Lefebore. (Çev. ve Dzn: Kofman, E. ve Lebas, E.) Oxford: Blackwell.

Litman, T. (2017). Evaluating transportation equity guidance for incorporating distributional impacts in transportation planning. Victoria Transport Policy Institute "Evaluating Transportation Equity," World Transport Policy \& Practice, 8(2), 50-65.. http://www.vtpi.org/equity.pdf adresinden erişilmiştir. (Originally published as Todd Litman 2002).

Mamun, S. (2011). Public transit accessibility and need indices: approaches for measuring service gap. University of Connecticut.

Marx, K. ve Engels, F., (1848). Manifest der kommunistischen partei.

Mekansal Planlar Yapım Yönetmeliği, (Haziran 6, 2014) Resmi Gazete. Sayı: 29030, 2014.https://www.mevzuat.gov.tr/Metin.Aspx?MevzuatKod=7.5.19788\&Mevzuatll iski=0\&sourceXmlSearch=mekansal, adresinden erişilmiştir.

Newman, P.W.G. ve Kenworthy, J.R. (1989a). Cities and automobile dependence: sourcebook. Aldershot: Gower.

Newman, P.W.G. ve Kenworthy, J.R. (1989b). Gasoline consumption and cities: a comparison of U.S. cities with a global survey. Journal of the American Planning Association, 55, 24-37. doi:10.1080/01944368908975398.

Rodriguez, J. P., Comtois, C. ve Slack, B. (2006). The geography of transport systems. Newyork: Routledge, $4^{\text {th }}$ Edition. https:/people.hofstra.edu/geotrans/ adresinden erişilmiştir.

Shlomo, O. (2016). Sub-formality in the formalization of public transport in East Jerusalem. The Open University of Israel.

The World Bank (2002). Cities on move. a world bank urban transport strategy review. Washington D.C.

Wacquant, L. (2008). Kent Paryaları:Illeri Marjinallĭ̆in Karşılaştırmah Sosyolojisi. Boğaziçi Üniversitesi Yayınevi: İstanbul.

Weisbrod, G. ve Reno, A. (2009). Economic impact of public transportation investments, American public transportation authority, (APTA) 2009, 1-77. http://www.apta.com/resources/reportsandpublications/Documents/economic_impact_of_public_transportation_investment.pdf. 